\title{
BMJ Open Neighbourhoods for Active Kids: study protocol for a cross-sectional examination of neighbourhood features and children's physical activity, active travel, independent mobility and body size
}

\author{
Melody Oliver, ${ }^{1}$ Julia McPhee, ${ }^{2}$ Penelope Carroll, ${ }^{3}$ Erika Ikeda, ${ }^{2}$ Suzanne Mavoa,,${ }^{3,4}$ \\ Lisa Mackay, ${ }^{2}$ Robin A Kearns, ${ }^{5}$ Marketta Kyttä, ${ }^{6}$ Lanuola Asiasiga, ${ }^{3}$ \\ Nicholas Garrett, ${ }^{7}$ Judy Lin, ${ }^{3}$ Roger Mackett, ${ }^{8}$ Caryn Zinn, ${ }^{2}$ \\ Helen Moewaka Barnes, ${ }^{3}$ Victoria Egli, ${ }^{2}$ Kate Prendergast, ${ }^{2}$ Karen Witten ${ }^{3}$
}

To cite: Oliver M, McPhee J, Carroll $\mathrm{P}$, et al. Neighbourhoods for Active Kids: study protocol for a cross-sectional examination of neighbourhood features and children's physical activity, active travel, independent mobility and body size. BMJ Open 2016:6:e013377.

doi:10.1136/bmjopen-2016013377

- Prepublication history for this paper is available online. To view these files please visit the journal online (http://dx.doi.org/10.1136/ bmjopen-2016-013377).

Received 7 July 2016 Accepted 21 July 2016

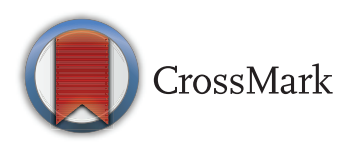

For numbered affiliations see end of article.

Correspondence to Dr Melody Oliver; melody.oliver.aut@gmail.com

\section{ABSTRACT}

Introduction: New Zealand children's physical activity, including independent mobility and active travel, has declined markedly over recent decades. The Neighbourhoods for Active Kids (NfAK) study examines how neighbourhood built environments are associated with the independent mobility, active travel, physical activity and neighbourhood experiences of children aged 9-12 years in primary and intermediate schools across Auckland, New Zealand's largest city.

Methods and analysis: Child-specific indices of walkability, destination accessibility and traffic exposure will be constructed to measure the built environment in 8 neighbourhoods in Auckland. Interactive onlinemapping software will be used to measure children's independent mobility and transport mode to destinations and to derive measures of neighbourhood use and perceptions. Physical activity will be measured using 7-day accelerometry. Height, weight and waist circumference will be objectively measured. Parent telephone interviews will collect sociodemographic information and parent neighbourhood perceptions. Interviews with school representative will capture supports and barriers for healthy activity and nutrition behaviours at the school level. Multilevel modelling approaches will be used to understand how differing built environment variables are associated with activity, neighbourhood experiences and health outcomes.

Discussion: We anticipate that children who reside in neighbourhoods considered highly walkable will be more physically active, accumulate more independent mobility and active travel, and be more likely to have a healthy body size. This research is timely as cities throughout New Zealand develop and implement plans to improve the liveability of intensifying urban neighbourhoods. Results will be disseminated to participants, local government agencies and through conventional academic avenues.

\section{Strengths and limitations of this study}

- Strengths of the study are the strategic school recruitment methods to ensure a large sample of children, heterogeneous in terms of socioeconomic deprivation, ethnicity, age and geographic location.

- The use of child-centred methods to collect information on children's use and perceptions of their neighbourhood environments is anticipated to garner unique insights that would not otherwise be captured.

- Objective measures of physical activity, body size and the neighbourhood built environment are key strengths.

- Limitations are that the data are cross-sectional, so causality cannot be implied. Data are being collected in one New Zealand city only. Nutrition and travel behaviours are being self-reported by children; however, the concurrent proxy reporting of these behaviours by parents will be used to improve accuracy of these variables.

\section{INTRODUCTION}

Physical activity is fundamental to optimal health, development and well-being in children. ${ }^{12}$ Even modest amounts of activity can have marked health benefits in high-risk children (eg, who are obese or have high blood pressure). ${ }^{3}$ Active travel (eg, walking or cycling to destinations) and independent mobility (ie, unsupervised travel and neighbourhood play) offer important opportunities for children to accumulate physical activity. ${ }^{4-6}$ Both behaviours offer numerous cobenefits-for example, active travel is associated with the maintenance of a healthy 
weight $^{7}$ and improved cardiovascular risk profiles. ${ }^{8}$ Independent mobility promotes ongoing navigation, risk assessment and decision-making by the child, providing learning opportunities not available when supervised by an adult. ${ }^{9}{ }^{10}$ Children's travel behaviours tend to be less structured than more purposeful adult activity and travel patterns. ${ }^{11}$ When a child is walking with an adult they travel faster and more linearly and purposively compared with when they travel alone or with peers. Without journey supervision, children are free to explore, play and undertake challenging activities (eg, climbing trees) that may be prohibited by safetyconscious parents. ${ }^{12}$

Despite such clear benefits, the prevalence of these behaviours is low in New Zealand children. ${ }^{13}$ While some evidence of flattening out has occurred, ${ }^{14}$ recent decades have mostly seen significant declines in these behaviours for children. ${ }^{15-17}$ Concurrently, increasing body sizes in New Zealand children have risen to the point that New Zealand has one of the highest rates of childhood overweight and obesity worldwide. $^{18}$ Neighbourhoods can provide children important opportunities to accumulate health-promoting levels of physical activity through active travel and independent mobility, being active at destinations (eg, parks) and generally 'colonising' local settings. ${ }^{19-21}$

Associations between children's physical activity and neighbourhood features such as dwelling density, destination accessibility, ${ }^{22}$ street connectivity ${ }^{23}{ }^{24}$ traffic exposure (negative), streets conducive to walking and cycling, ${ }^{25}$ park space and multiuse path space ${ }^{26}$ have been observed. A time-use examination of weekend physical activity in children aged 5-17 years revealed associations between physical activity and destination availability, dwelling density and active transport infrastructure. ${ }^{11}$ Regional and sociodemographic differences have been observed; for example, one recent US investigation revealed that areas profiled as having higher walkability and recreation/park access were associated with children's moderate-to-vigorous physical activity (MVPA) accumulated out of school hours in one study region (San Diego), but not another (Seattle/King County). ${ }^{27}$ In older (12-15 years), but not younger, children higher dwelling density and street connectivity have been associated with increased physical activity, ${ }^{24}$ although lower dwelling density has also been found to increase out-of-school physical activity. ${ }^{11}$

Distance to school has consistently been the strongest built environment factor linked with children's active travel to school, ${ }^{28}{ }^{29}$ and to neighbourhood destinations in general. ${ }^{25}$ However, associations between other built environment factors and active travel (or independent mobility) is limited and inconsistent, with findings often varying by age, sex, ethnicity and socioeconomic factors. ${ }^{22} 3031$ Some work has shown higher street connectivity and lower traffic volumes are associated with active travel to school, while others have shown conflicting results. ${ }^{32}$
Rapid urbanisation and limited planning for children in urban environments has led to increasingly constrained opportunities for children's engagement with their neighbourhood. ${ }^{33} 34$ While these changes likely reduce activity behaviours overall, there are also examples of the resilience and innovative capacity of children to reframe what an activity-friendly environment means to them. For example, recent work with Auckland children revealed a high use of 'third place thresholds' (eg, driveways, grass verges, stairwells, etc) for play opportunities. $^{21}$ Such research that considers children as active agents in the research process, using child-centred methods, and gathering information from children's perspectives, provides unique strengths in terms of identifying features and issues of importance that might not otherwise be captured. ${ }^{35}$

Other challenges exist in terms of understanding the impact of the built neighbourhood environment on children's activity behaviours and health outcomes. Neighbourhood delineation is perhaps the greatest issue ${ }^{36}$ with differential relationships with activity observed by neighbourhood buffer type (eg, Euclidean, street network) and buffer size (eg, 400 and $800 \mathrm{~m}) \cdot{ }^{26} \mathrm{In}$ part this is likely due to the "constant neighbourhood size trap, ${ }^{37}$ recognising that individuals have different levels of exposure to their local neighbourhood, and that the shapes of these 'activity spaces' may also differ. ${ }^{38} 39$

Parenting practices are an additional consideration as parents act as gatekeepers to children's everyday mobility. ${ }^{40}$ Car reliance, time scarcity, safety-conscious parenting practices, technology use and decline in traditional neighbourhood relationships are among the potential contributing factors in the decrease in children's independent mobility and neighbourhood physical activity. ${ }^{41}$ Parental concern about their child's safety appears to be the greatest social factor influencing children's active travel and independent mobility, ${ }^{10}{ }^{43}$ with 'good parenting practice' conceived as chauffeuring children to a wide range of activities and destinations. ${ }^{44}$ Paradoxically, this 'social trap' created by parents chaperoning children in cars, is of immediate public health significance as it reduces passive surveillance of those children who remain on the street (the safety in numbers effect). ${ }^{45}$ Furthermore, this practice reduces driver's awareness and safety practices relating to pedestrians.

The Neighbourhoods for Active Kids (NfAK) study aims to gain a deeper understanding of the relationship between the urban environment and children's activity behaviours and health outcomes. Data will be collected with children, their parents and school representatives using a range of measures to assess factors of importance across the home, school, and neighbourhood physical and social environments. A focus of this research is the use of child-centred participatory geographic information systems (GIS) methods to gather information on children's travel, independent mobility and neighbourhood perceptions, experiences and engagement. 


\section{DESIGN AND METHODS}

NfAK is a cross-sectional study with children aged 912 years, residing in Auckland, New Zealand's largest city ( 1.4 million residents, comprising $30 \%$ of the total population). Children are being recruited through intermediate (middle/junior high) schools (7-8 years, approximate ages 11-12 years) and a contributing primary school (including children from 5-6 years only, ages $9-10$ years) across eight neighbourhoods. Sample size calculations showed $\sim 125$ children per neighbourhood (ie, primary and intermediate school dyad), and at least 8 neighbourhoods (16 schools and 1000 participants in total) will be required to enable the detection of meaningful and significant differences in active travel, independent mobility and MVPA (with power of 0.8 and significance set at $\alpha=0.05$ ).

Information is being collected with children (body size, accelerometry, interactive mapping softGIS survey), their parents (computer-aided telephone interview, CATI) and school representatives (face-to-face interview). A range of GIS-based measures of the neighbourhood environment will be developed. Data collection started in February 2015, and is anticipated to be complete by September 2016.

\section{Neighbourhood selection}

For the purposes of this study, a study neighbourhood is defined as the catchment area around a state coeducation intermediate school (7-8 years) and a contributing primary school (1-6 years). Diversity in the population sample across key variables is facilitated by use of a matrix encompassing neighbourhood-level socioeconomic, walkability and destination accessibility features to identify areas for recruitment. Child-specific neighbourhood walkability, ${ }^{32}$ and child-specific neighbourhood destination accessibility (NDAI-C) ${ }^{46}$ have been calculated for each intermediate school in Auckland. Schools in the highest and lowest tertiles for these variables are then tabulated against their decile rating (an area-level measure of socioeconomic deprivation). ${ }^{47}$ Schools are identified for invitation from this matrix to ensure a spread across decile ratings (high, medium, low). Geographic spread across the city is also being considered in neighbourhood selection.

\section{School and participant recruitment}

Principals or deputy principals of each school (one intermediate school and a contributing primary school within each neighbourhood) are approached (by phone, email, face-to face) with an invitation for their school to participate in the study. They are provided with information sheets for the principal and teachers. Following school representative consent, students from classes of appropriate school years (selected by the school) are visited at the school by members of the research team, during class time, provided with verbal and written information about the study and invited to participate. Researchers are available to answer any questions the students or teachers have at this time. Participant information sheets, assent forms and parent consent forms are left with students, who are given 2 weeks to return their assent and parent consent forms if they wish to participate. Schools are provided a summary report of findings for their school and koha (voucher) to acknowledge their time and support of the study at completion of data collection for their school.

\section{Child measurement protocols}

Trained researchers visit the school during school hours to collect data with child participants. During this time, participants complete an online interactive mapping survey (softGIS), have their body size measured and are fitted with their accelerometer as detailed below. Children are asked to wear the accelerometers over 7 consecutive days, recording attachment and removal of the devices daily in a compliance diary. Approximately 8 days after the first school visit, a research assistant returns to the school to collect accelerometers and compliance diaries. Participants are provided with a report of their physical activity results and koha (shopping mall voucher) to acknowledge their contribution to the study.

\section{Physical activity}

Participants are fitted with Actigraph GT3X+ accelerometers fixed to an elastic belt (Actigraph, Pensacola, Florida, USA), worn around the waist. ${ }^{48-50}$ Units are initialised and data downloaded in Actilife V.6. A raw data sample frequency of $30 \mathrm{~Hz}$ is being specified, and all download options are checked (ie, steps, lux, inclinometer, low frequency extension enabled). Downloaded data are being screened at the completion of each school to identify any obvious accelerometer malfunctions or outliers. ${ }^{51}$ Files are then converted to .csv within Meterplus (Santech, San Diego, California, USA) and accelerometer count thresholds of Evenson et $a \tilde{l}^{2}$ employed to classify time spent sedentary and in MVPA. Non-wear time is being classified as $60 \mathrm{~min}$ or more of consecutive zero counts. ${ }^{53}$ At least 7 hours of data are required for a valid day, and at least 3 valid days are required for inclusion in analyses of physical activity. ${ }^{54}$

\section{Body size}

Height $(\mathrm{m})$, weight $(\mathrm{kg})$ and waist circumference $(\mathrm{cm})$ are being measured using a stadiometer, Seca scales and Lufkin tape measure, respectively. Body mass index (BMI) will be calculated as $\mathrm{kg} / \mathrm{m}^{2}$ and thresholds for BMI-derived overweight and obesity ${ }^{55}$ and height-to-waist circumference $^{56}$ employed. Body size measures are being taken by trained researchers, in the same room as other participants, but behind a partial screen for privacy.

\section{softGIS survey}

An interactive, spatially referenced online survey tool is being used to capture survey items with children and conduct mapping exercises of routes to school and 
neighbourhood destinations of importance. ${ }^{57}$ Prior to implementation in the current study, the survey was tailored for local use and piloted with children across a range of ages and technical skill levels. Subsequent adaptations to the survey were: removal of some items (eg, to shorten survey duration); reducing or rewording items (eg, items requiring estimation of portion sizes of food servings because this was too difficult); and adding an item to assess whether participants who were driven to school were comfortable to try mapping their route to school. Although children who walked, cycled or scootered to school were confident in the route mapping exercise, children who were driven often had difficulty describing their route to school. In contrast with earlier research, it was also identified that additional researcher support was required to aid children's comprehension and comfort in completing the survey. Accordingly, a maximum of four participants complete the survey at any given time, with four researchers available to provide one-to-one assistance with survey completion.

The neighbourhood mapping components of the survey was drawn from the earlier work of Kyttä et $a l^{57}$ Respondents are asked to indicate, on the online map, places they go in and around their neighbourhood. This item is intentionally open for interpretation by the child, in terms of defining 'neighbourhood' and identifying places of importance to them. On marking a destination, additional items on travel mode to that destination, accompaniment (alone, with other children but no adults, with an adult present), open-ended items about likes and dislikes and a 10 point sliding scale of how much the participant liked that destination (I do not like it here, I like it a lot) are asked. Children are also asked if there were other places they would like to go, but are not allowed to and if so, where they would like to go and what they would do there.

School travel: Usual mode(s) of travel to school are selfreported, and participants are asked to map their usual route to school, to report the frequency of travelling this route (all of the time, most of the time, sometimes, hardly ever/never), and asked about likes, dislikes and perceptions about their route to school. Fifteen items to assess motivations for travel behaviours have been drawn from earlier research using the reasoned action approach construct. ${ }^{58} 59$

Perceived neighbourhood and road safety is being assessed using four items regarding traffic volume around the school, volume of parked cars around the school, and sense of safety in the neighbourhood when with and without an adult. ${ }^{60}$

Use of third places is being captured using open and closed items to assess whether children play outside near their residence (eg, driveway, carpark, stairwell/foyer/ corridor). ${ }^{21}$ Accompaniment status when playing in these spaces is also captured (alone, with other children but no adults, an adult is present).

Independent mobility licence is being assessed using items from the Policy Studies Institute study of children's independent mobility. ${ }^{15}$ Children are asked whether they are allowed to cross main roads on their own, cycle on main roads, go on local public transport on their own and cycle to local destinations (eg, friends) on their own. Participants are also asked whether they are allowed to do the following activities, by themselves, with other children (with no adult present), only if an adult was around or not at all: go to clubs/activities, go to the city centre/shopping malls, go to parks/sports facilities, go out alone after dark or go to their friends' houses.

Nutrition and food purchasing behaviours are measured using adapted items from the New Zealand Health Survey $^{61}$ and the New Zealand Child Nutrition Survey. ${ }^{62}$ Pilot testing of the survey revealed a need to substantially simplify items to aid comprehension. Accordingly, children are being asked how often they: (1) consumed sugar-sweetened beverages such as fruit juice, fizzy drinks, cordial or sports drinks, (2) consumed foods such as sweet biscuits, chocolate, lollies (sweets), chips (crisps), cakes etc., (3) bought something to eat or drink on the way to school, (4) bought something to eat or drink on the way home from school and (5) bought food or drinks from school. Response options for all items are: every day, every week, every month, hardly ever/never or not sure. Images of example foods and drinks are also provided to aid comprehension.

\section{School environment and policy}

Telephone or face-to-face interviews are being conducted with a representative from each school (usually the principal or deputy principal). Interviews are semistructured, with specific items around school policies and practices related to school travel (eg, walking school buses) and the school nutrition and physical activity environment.

School demographic information (total roll, ethnic composition, etc) is being obtained from the Ministry of Education 'education counts' website (http://www. educationcounts.govt.nz).

\section{Home/family environment}

Following conclusion of data collection within child participants, a CATI is being conducted with parents/caregivers of participating children. Surveys are delivered in English, Samoan, Tongan, Chinese or Korean, as required.

Sociodemographic and household factors are reported by parents/caregivers as follows: child ethnicity, sex, date of birth; house type, household composition, access to outdoor space (own garden, shared outdoor area, nearby park), home ownership status, car availability; and respondent's highest qualification, current employment situation and ethnicity. Socioeconomic status is being assessed using one item from the New Zealand Index of socioeconomic deprivation for individuals around having to purchase cheaper food in order to pay for other items. ${ }^{63}$ 
School travel: Usual mode of travel to and from school, accompaniment for these school trips, reasons for travel mode decision-making, relative importance of reasons, and role of trip chaining in school travel decisionmaking are being captured using items from the Kids in the City Study. ${ }^{64}$

Independent mobility licence is being assessed using items from the Policy Studies Institute as described above. ${ }^{15}$ Respondents are also asked if their child has a mobile phone and if so, whether this gives them (the respondent) more confidence in letting their child to go out on their own. An open-ended item is used to identify factors that would make it better for children to travel independently in their neighbourhood.

Perceptions of neighbourhood safety, social cohesion and social connectedness are being captured using adapted items from Sampson et al. ${ }^{6566}$

Usual time spent sitting in specific behaviours (watching television/videos/DVDs; using the computer, tablets or playing video games; reading, writing or doing homework not using the computer; riding in a car, bus, etc) is proxy-reported by parents/caregivers for their child, for weekdays and weekend days. ${ }^{67}$

Child nutrition behaviours are captured using items from the New Zealand Health Survey and Child Nutrition Survey as above, and include additional items on usual servings of fruit and vegetables per day. ${ }^{61} 62$

\section{Streetscape audits}

Pedestrian and cycling infrastructure, safety and aesthetic features of streets near participating schools will be audited using the New Zealand Systematic Pedestrian and Cycling Environment Scan a tool adapted for and used in New Zealand. ${ }^{68}$ Segments will be audited virtually using Google Street View. ${ }^{69}$

\section{Weather}

Daily weather data (precipitation, hours of daylight, minimum and maximum temperature) will be freely downloaded from the New Zealand meteorological service (cliflo.niwa.co.nz).

\section{GIS measures}

GIS measures of the neighbourhood environment will be derived around each participant's residential and school address based on distance along the pedestrian network. Geographic data sets will be extracted using ArcGIS V.10.2 (ESRI, Redlands, California, USA). SoftGIS map data (polylines) will be imported into ArcGIS. A range of buffer sizes will be employed, and the utility of the softGIS neighbourhood destination mapping data to inform appropriate activity space buffers will be investigated. The following variables will be calculated:

Individual walkability measures: net residential density (ratio of residential dwellings to residential land area), street network connectivity (ratio of number of intersections with three or more intersecting streets per square kilometre to land area) and land use mix (an entropy index based on the presence or absence of five types of land use) will be calculated. ${ }^{70}$

A child-specific walkability index will be generated using: (1) the ratio of high-speed roads $(>60 \mathrm{~km} /$ hour) to lowspeed roads and (2) the ratio of the pedestrian network area to the maximum possible area within the defined boundary. ${ }^{32}$

Child-specific destination accessibility will be determined using the neighbourhood destination accessibility index for children. ${ }^{71}$

Availability of public open space will be calculated as the ratio of public open space (green space, parks, playgrounds) that can be freely accessed by the public to the total neighbourhood area. ${ }^{72}$

Coastal access will be calculated using the shortest street network distance from the residential address to the closest access point.

Distance to school: participant-drawn routes to school will be used to calculate the distance to school. In the likelihood that these data will not be collected for all participants, estimated distance to school will also be generated using the shortest street network distance from home to school. ${ }^{73}$

Food outlet data will be collected from local authorities and classification protocols of Vandevijvere et $a l^{74}$ applied to determine density of food outlets deemed healthy, partly healthy and unhealthy.

\section{DATA ANALYSIS}

Initial statistical analyses will be primarily descriptive presenting frequencies, medians and IQRs or means and SDs where applicable. Distributions of outcome variables will be examined to determine the most appropriate statistical model for the multivariate modelling. Multilevel general linear, Poisson, or logistic modelling (depending on appropriate outcome distributions), will be used to examine associations between neighbourhood built environment and children's outcome measures (physical activity, active travel and independent mobility) at both individual and neighbourhood levels. The outcome variables will be adjusted for demographic (including socioeconomic) variables, weather and where relevant, nutritional measures. Models will include intraneighbourhood correlation (schools and classes) as random effects. A best subset method will be used for model selection and diagnostics testing will determine if model assumptions are adequately met. All analyses will be run in SAS V.9.2.

\section{DISCUSSION}

Built environments that promote sustainable increases in physical activity in children (as well as adults) have the potential to improve population health and reduce chronic disease in the short and long terms. This study is the first to use online interactive mapping methods such as softGIS to investigate how neighbourhood built 
environment features are associated with independent mobility, active transport and physical activity of young children aged 9-12 years. Use of this emerging methodology facilitates a greater understanding of these relationships by capturing detailed information about child-specific neighbourhood destinations visited, as well as travel modes to, and perceptions of, these features. A child-centred approach enables the collection of information about neighbourhood features and destinations and travel and activity behaviours that would not be captured using traditional adult or researcher-centred methods. Alongside this detailed examination of neighbourhood environments, objective measures of physical activity and body size, as well as data collected about the family and school contexts, will provide an in-depth understanding of relationships between neighbourhoods and health from a socioecological perspective. Results will be disseminated to participants, local government agencies and urban planners, and through conventional academic avenues (presentations at scientific conferences, peer-reviewed academic journal publications).

We anticipate that children who reside in neighbourhoods considered highly walkable (ie, characterised by higher street connectivity, dwelling density, destination accessibility and streetscape safety and aesthetics) will be more physically active, accumulate more independent mobility and active travel, and be more likely to have a healthy body size. Findings will provide evidence needed to inform the design of urban areas as cities continue to intensify internationally, and to inform policy on redevelopment of established urban areas. It is vital that children are provided with opportunities to develop healthy mobility and physical activity patterns for their current and future well-being. Well-designed built environments that take children's needs into consideration may be fundamental to encouraging these health-promoting behaviours.

\author{
Author affiliations \\ ${ }^{1}$ School of Nursing, the University of Auckland, Auckland, New Zealand \\ ${ }^{2}$ Human Potential Centre, Auckland University of Technology, Auckland, \\ New Zealand \\ ${ }^{3}$ SHORE and Whāriki Research Centre, School of Public Health, Massey \\ University, Auckland, New Zealand \\ ${ }^{4}$ McCaughey VicHealth Centre for Community Wellbeing, School of Population \\ and Global Health, the University of Melbourne, Melbourne, Australia \\ ${ }^{5}$ School of Environment, the University of Auckland, Auckland, New Zealand \\ ${ }^{6}$ Department of Real Estate, Planning and Geoinformatics, Aalto University, \\ Helsinki, Finland \\ ${ }^{7}$ Department of Epidemiology and Biostatistics, Auckland University of \\ Technology, Auckland, New Zealand \\ ${ }^{8}$ University College London, London, UK
}

Acknowledgements The authors gratefully acknowledge the time and support of the schools, students and parents/caregivers involved in this research.

Contributors MO, KW, RAK, PC, SM, JL and LA conceived the study. El, LM, VE and KW provided expertise on data collection protocols, HMB provided specific input for cultural appropriateness and dissemination of participant and school results, MK provided specialist advice on softGIS, and RM provided expert input on measurement of independent mobility. NG provided expertise in biostatistical analyses and sample size calculations. CZ provided specialist input in survey measures of nutrition-related behaviours. JM developed the first draft of this manuscript. All authors contributed to development of the study protocols and approved the final manuscript.

Funding This study was supported by the Health Research Council of New Zealand (grant number 14/436)

Competing interests None declared.

Ethics approval Ethical approval to conduct the study was provided by the host institution ethics committees (AUTEC Committee (AUTEC, 14/263, 3 September 2014; MUHECN 3 September 2014; UAHPEC 9 September 2014).

Provenance and peer review Not commissioned; peer-reviewed for ethical and funding approval prior to submission.

Open Access This is an Open Access article distributed in accordance with the Creative Commons Attribution Non Commercial (CC BY-NC 4.0) license, which permits others to distribute, remix, adapt, build upon this work noncommercially, and license their derivative works on different terms, provided the original work is properly cited and the use is non-commercial. See: http:// creativecommons.org/licenses/by-nc/4.0/

\section{REFERENCES}

1. Strong WB, Malina RM, Blimkie CJ, et al. Evidence based physical activity for school-age youth. J Pediatr 2005;146:732-7.

2. World Health Organization. Global recommendations on physical activity for Health. Geneva: World Health Organization, 2010.

3. Janssen I, Leblanc AG. Systematic review of the health benefits of physical activity and fitness in school-aged children and youth. Int J Behav Nutr Phys Act 2010;7:40.

4. Oliver M, Parker K, Witten K, et al. Children's out-of-school independently mobile trips, active travel, and physical activity: a cross-sectional examination from the Kids in the City study. $J$ Phys Act Health 2016;13:318-24.

5. Schoeppe S, Duncan MJ, Badland HM, et al. Associations between children's independent mobility and physical activity. BMC Public Health 2014;14:91.

6. Schoeppe S, Duncan MJ, Badland HM, et al. Associations between children's active travel and levels of physical activity and sedentary behavior. J Transport Health 2015;2:336-42.

7. Gordon-Larsen P, Nelson MC, Beam K. Associations among active transportation, physical activity, and weight status in young adults. Obes Res 2005;13:868-75.

8. Cooper AR, Wedderkopp $\mathrm{N}$, Wang $\mathrm{H}$, et al. Active travel to school and cardiovascular fitness in Danish children and adolescents. Med Sci Sports Exerc 2006;38:1724-31.

9. Prezza M. Children's independent mobility: a review of recent Italian literature. Children, Youth and Environments 2007;17:293-318.

10. Badland HM, Oliver M. Child Independent Mobility: Making the Case, and Understanding How the Physical and Social Environments Impact on the Behaviour. In: Turunen E, Koskinen A, eds. Urbanization and the global environment. New York: NOVA Science Publishers, 2011:51-79.

11. Copperman RB, Bhat CR. An analysis of the determinants of children's weekend physical activity participation. Transportation 2007:34:67-87.

12. Mackett RL, Paskins J, Gong Y, et al. Children's Local Travel Behaviour-How the Environment Influences, Controls, and Facilitates It. 11th World Conference on Transport Research; 24-28 June 2007; Berkeley, CA.

13. Maddison R, Marsh S, Hinckson E, et al. Results from the New Zealand 2016 Report Card on Physical Activity for Children and Youth. J Phys Act Health 2016. In press.

14. Ministry of Transport. Travel Patterns: Household Travel. Secondary Travel Patterns: Household Travel. 2014. http://www.transport.govt. nz/ourwork/tmif/travelpatterns/tp007/

15. Shaw B, Bicket M, Elliott B, et al. Children's independent mobility. An International Comparison and Recommendations for Action London, UK: Policy Studies Institute, 2015.

16. Ministry of Transport. New Zealand Household Travel Survey 20082011-Comparing Travel Modes. Wellington, New Zealand: Ministry of Transport, 2012.

17. Fyhri A, Hjorthol R, Mackett RL, et al. Children's active travel and independent mobility in four countries: development, social contributing trends and measures. Transport Policy 2011;18:703-10.

18. Wang $Y$, Lobstein T. Worldwide trends in childhood overweight and obesity. Int J Pediatr Obes 2006;1:11-25. 
19. Hooper CM, Ivory VC, Fougere G. Childhood neighbourhoods as third places: developing durable skills and preferences that enhance wellbeing in adulthood. Health Place 2015;34:34-45.

20. Rogers M. 'They are there for you': the importance of neighbourhood friends to children's well-being. Child Indicators Res 2012;5: 483-502

21. Carroll P, Witten K, Kearns R, et al. Kids in the City: children's use and experiences of urban neighbourhoods in Auckland, New Zealand. J Urban Des 2015;20:417-36.

22. Giles-Corti B, Kelty SF, Zubrick SR, et al. Encouraging walking for transport and physical activity in children and adolescents: how important is the built environment? Sports Med 2009;39:995-1009.

23. de Vries SI, Bakker I, van Mechelen W, et al. Determinants of activity-friendly neighbourhoods for children: results from the SPACE study. Am J Health Promot 2007;21:312-16.

24. Frank L, Kerr J, Chapman J, et al. Urban form relationships with walk trip frequency and distance among youth. Am J Health Promot 2007:21:305-11.

25. Oliver M, Mavoa S, Badland $\mathrm{H}$, et al. Associations between the neighbourhood built environment and out of school physical activity and active travel: an examination from the Kids in the City study. Health Place 2015;36:57-64.

26. Mitchell CA, Clark AF, Gilliland JA. Built environment influences of children's physical activity: examining differences by neighbourhood size and sex. Int J Env Res Pub He 2016;13:130

27. Kurka JM, Adams MA, Todd M, et al. Patterns of neighborhood environment attributes in relation to children's physical activity. Health Place 2015;34:164-70.

28. McDonald NC. Children's mode choice for the school trip: the role of distance and school location in walking to school. Transportation 2008;35:23-35.

29. Oliver M, Badland $\mathrm{H}$, Mavoa $\mathrm{S}$, et al. Environmental and socio-demographic associates of children's active transport to school: a cross-sectional investigation from the URBAN Study. Int J Behav Nutr Phys Act 2014;11:70.

30. Davison KK, Lawson CT. Do attributes in the physical environment influence children's physical activity? A review of the literature. Int J Behav Nutr Phys Act 2006;3:19.

31. Kerr J, Rosenberg D, Sallis JF, et al. Active commuting to school: associations with environment and parental concerns. Med Sci Sports Exerc 2006;38:787-94.

32. Giles-Corti B, Wood G, Pikora T, et al. School site and the potential to walk to school: the impact of street connectivity and traffic exposure in school neighborhoods. Health Place 2011;17:545-50.

33. Zeiher H. Children's islands in space and time: the impact of spatial differentiation on children's ways of shaping social life. In: Krüger $\mathrm{HH}$, Bois-Reymond MS, Sünker H, eds. Childhood in Europe, Approaches-Trends-Findings. New York: Peter Lang, 2001:139-59.

34. Kyttä M. Children in outdoor contexts. Affordances and independent mobility in the assessment of environmental child friendliness. Saarbrücken, Germany: VDM Verlag Dr. Müller, 2008.

35. Malone K, Rudner J. Global perspectives on children's independent mobility: a socio-cultural comparison and theoretical discussion of children's lives in four countries in Asia and Africa. Global Studies of Childhood 2011;1:243-59.

36. Oliver M, Schoeppe S, Mavoa S, et al. Children's geographies for activity and play: an overview of measurement approaches. Singapore: Springer, 2016.

37. Vallée J, Le Roux G, Chaix B, et al. The 'constant size neighbourhood trap' in accessibility and health studies. Urban Studies 2015;52:338-57.

38. Villanueva K, Giles-Corti B, Bulsara M, et al. How far do children travel from their homes? Exploring children's activity spaces in their neighborhood. Health Place 2012;18:263-73.

39. Lee NC, Voss C, Frazer AD, et al. Does activity space size influence physical activity levels of adolescents?-A GPS study of an urban environment. Prev Med Rep 2016;3:75-8.

40. Pont K, Ziviani J, Wadley D, et al. Environmental correlates of children's active transportation: a systematic literature review. Health Place 2009;15:849-62

41. Carver A, Timperio A, Crawford D. Perceptions of neighborhood safety and physical activity among youth: the CLAN study. J Phys Act Health 2008:5:430-44.

42. Mackett RL. Children's travel behaviour and its health implications. Transport Policy 2013;26:66-72.

43. Panter JR, Jones AP, van Sluijs EMF, et al. Attitudes, social support and environmental perceptions as predictors of active commuting behaviour in school children. $J$ Epidemiol Community Health 2010;64:41-8.

44. Dunn J, Kinney D, Hofferth SL. Parental ideologies and children's after-school activities. Am Behav Sci 2003:46:1359-86.

45. Tranter P, Pawson E. Children's access to local environments: a case-study of Christchurch, New Zealand. Local Environ 2001;6:27-48.

46. Witten K, Pearce J, Day P. Neighbourhood Destination Accessibility Index: a GIS tool for measuring infrastructure support for neighbourhood physical activity. Environ Plan A 2011;43:205-23.

47. Ministry of Education. School Deciles. Secondary School Deciles March 23, 2016. 2016. http://www.education.govt.nz/school/ running-a-school/resourcing/operational-funding/ school-decile-ratings/

48. Ozemek C, Kirschner MM, Wilkerson BS, et al. Intermonitor reliability of the GT3X+ accelerometer at hip, wrist and ankle sites during activities of daily living. Physiol Meas 2014;35: 129-38.

49. Lee JA, Williams SM, Brown DD, et al. Concurrent validation of the Actigraph gt3x+, Polar Active accelerometer, Omron HJ-720 and Yamax Digiwalker SW-701 pedometer step counts in lab-based and free-living settings. J Sports Sci 2015;33:991-1000.

50. Jarrett $H$, Fitzgerald L, Routen AC. Interinstrument reliability of the ActiGraph GT3X+ ambulatory activity monitor during free-living conditions in adults. J Phys Act Health 2015;12:382-7.

51. Cain KL. IPEN Adolescent Accelerometer Scoring Protocol. Secondary IPEN Adolescent Accelerometer Scoring Protocol. 2013. http://www.ipenproject.org/methods_accelerometers.html

52. Evenson KR, Catellier DJ, Gill K, et al. Calibration of two objective measures of physical activity for children. $J$ Sports Sci 2008;26:1557-65

53. Oliver M, Badland HM, Schofield GM, et al. Identification of accelerometer nonwear time and sedentary behavior. Res $Q$ Exerc Sport 2011:82:779-83.

54. Mattocks C, Leary S, Ness A, et al. Intraindividual variation of objectively measured physical activity in children. Med Sci Sports Exerc 2007:39:622-9.

55. Cole TJ, Bellizzi MC, Flegal KM, et al. Establishing a standard definition for child overweight and obesity worldwide: international survey. BMJ 2000;320:1240-5.

56. Taylor RW, Jones IE, Williams SM, et al. Evaluation of waist circumference, waist-to-hip ratio, and the conicity index as screening tools for high trunk fat mass, as measured by dual-energy X-ray absorptiometry, in children aged 3-19 y. Am J Clin Nutr 2000;72:490-5.

57. Kyttä AM, Broberg AK, Kahila MH. Urban environment and children's active lifestyle: SoftGIS revealing children's behavioral patterns and meaningful places. Am J Health Promot 2012;26: e137-48.

58. Fishbein M, Ajzen I. Predicting and changing behavior: the reasoned action approach. New York, NY: Psychology Press, 2010.

59. Murtagh S, Rowe DA, Elliott MA, et al. Predicting active school travel: the role of planned behavior and habit strength. Int J Behav Nutr Phys Act 2012;9:65.

60. Mullan E. Do you think that your local area is a good place for young people to grow up? The effects of traffic and car parking on young people's views. Health Place 2003;9:351-60.

61. Ministry of Health. Methodology Report for the 2006/07 New Zealand Health Survey. Wellington, New Zealand: Ministry of Health, 2008.

62. Ministry of Health. NZ Food, NZ Children. Key Results of the 2002 National Children's Nutrition Survey. Wellington, New Zealand: Ministry of Health, 2003.

63. Salmond C, Crampton P, King P, et al. NZiDep: a New Zealand index of socioeconomic deprivation for individuals. Soc Sci Med 2006;62:1474-85

64. Oliver M, Witten K, Kearns RA, et al. Kids in the City Study: research design and methodology. BMC Public Health 2011;11:587.

65. Sampson RJ, Raudenbush SW. Systematic social observation of public spaces: a new look at disorder in urban neighborhoods ${ }^{1}$. Am J Sociol 1999;105:603-51

66. Sampson RJ, Raudenbush SW, Earls F. Neighborhoods and violent crime: a multilevel study of collective efficacy. Science 1997; $277: 918-24$

67. Marshall SJ, Biddle SJH, Sallis JF, et al. Clustering of sedentary behaviours and physical activity among youth: a cross-national study. Pediatric Exercise Science 2002;14:401-17.

68. Witten K, Blakely T, Bagheri N, et al. Neighborhood built environment and transport and leisure physical activity: findings using objective exposure and outcome measures in New Zealand. Environ Health Perspect 2012;120:971-7. 
69. Badland HM, Opit S, Witten K, et al. Can virtual streetscape audits reliably replace physical streetscape audits? J Urban Health 2010;87:1007-16.

70. Frank LD, Sallis JF, Conway TL, et al. Many pathways from land use to health: associations between neighborhood walkability and active transportation, body mass index, and air quality. J Am Plan Assoc 2006;72:75-87.

71. Badland HM, Donovan P, Mavoa S, et al. Assessing neighbourhood destination access for children: development of the NDAI-C audit tool. Environment and Planning B: Planning and Design 2015;42:1-13.
72. Badland HM, Keam R, Witten $\mathrm{K}$, et al. Examining public open spaces by neighborhood-level walkability and deprivation. J Phys Act Health 2010;7:818-24.

73. Thornton LE, Pearce JR, Kavanagh AM. Using Geographic Information Systems (GIS) to assess the role of the built environment in influencing obesity: a glossary. Int J Behav Nutr Phys Act 2011;8:71.

74. Vandevijvere S, Sushil Z, Exeter DJ, et al. Obesogenic Retail Food Environments Around New Zealand Schools: a National Study. Am J Prev Med 2016. In press. doi:10.1016/. amepre.2016.03.013 